\title{
Entrevista com John Downing
}

Entrevista concedida a Patrícia Wittenberg Cavalli, pesquisadora do Observatório Mídia Regional- Programa de Pós-Graduação em Comunicação e Artes - Universidade Federal de Pernambuco. E-mail: patwittenberg@gmail.com

\section{RESUMO}

Pela quarta vez no Brasil, John Downing, pesquisador britânico e professor da Southern Illinois University EUA esteve em Recife na segunda semana de novembro de 2008, para palestrar no IV Encontro de Mídia Cidadã. Sempre crítico em suas colocações, Downing dedicou vinte oito anos de pesquisa em mídia radical a serviço daqueles que querem mudar o curso da história.

\section{PALAVRAS-CHAVE}

movimentos sociais

racismo

mídia radical alternativa

\section{ABSTRACT}

Visiting Brazil for the fourth time, John Downing - British researcher and professor at Southern Illinois University - came to Recife on the second week of November, 2008, to deliver a talk on IV Encontro de Mídia Cidadã. Always critical on his positions, Downing dedicated 28 years of his carrier researching radical media at the service of those interested in changing the course of history.

\section{KEY WORDS}

social movementes

racism

alternative radical media
Há vinte oito anos, o pesquisador britânico John Downing, mais conhecido no Brasil pelo seu livro Mídia Radical Alternativa - Rebeldia nas Comunicações e Movimentos Sociais dedica-se a estudar e pesquisar mídias não convencionais. Há quarenta anos ele também frequenta as salas de aula como professor, instigando os seus alunos a ver a mídia como uma forma de democracia. Downing acredita que a dignidade do cidadão não é só ter o direito a saúde e educação, mas também a comunicação. Esta entrevista com este pesquisador irreverente foi realizada em duas etapas. Em 2004, nos encontramos em Porto Alegre, agora, o encontro ocorreu em Recife, na mesma semana em que Downing ministrou palestra no IV Encontro de Midia Cidadã, evento promovido pelo Observatório da Mídia Regional da Universidade Federal de Pernambuco. Nesta entrevista, John, como gosta de ser chamado, nos conta o que enxerga nas entrelinhas da mídia e nos fala também sobre a preparação de uma Enciclopédia sobre Movimentos Sociais.

Patrícia Wittenberg- Há quatros anos, quando nos encontramos pela primeira vez, o senhor me dizia que a situação da grande mídia era triste. Como a encontra agora?

John Downing - A situação da grande mídia é um problema bem mais triste agora do que era antes por causa da concentração, que continua dos proprietários desse tipo de mídia. As grandes companhias globais continuam se fundindo e isso dá medo quanto ao futuro da democracia, porque sem um sistema de mídia aberta e que inclua todas as vozes de uma sociedade é um perigo para a democracia de qualquer país. Quanto a situação das pequenas mídias, como por exemplo, as mídias dos movimentos sociais, na minha opinião, elas vão por um caminho bem melhor.

PW - O senhor, em parceria com o sociólogo Charles Husband, escreveu cinco livros sobre racismo. Além desses foi autor, junto com Ali Mohammadi e Annabele Sreberny, de Questionando a Mídia, uma Introdução Crítica que foi um best-seller já na sua primeira edição. Apesar dessa extensa produção, o livro que mais causou repercussão no Brasil foi Mídia Radical - Rebeldia nas Comunicações e Movimentos Sociais, lançado aqui no país em 2002. Este livro o transformou aqui no Brasil quase que como o "pesquisador das mídias radicais". Isto lhe inquieta um pouco?

JD - Não exatamente que isto me inquiete ou me incomode, mas eu gostaria que as pessoas soubessem que eu estudo e publico sobre outros assuntos também. Em particular sobre racismo e as mídias da Inglaterra 
e dos Estados Unidos. E também sobre as mídias da antiga União Soviética e países satélites. E a importância desta experiência lá é de compreender como as grandes e também as pequenas mídias influenciam as grandes mudanças políticas e econômicas que fizeram o bloco soviético se desenvolver durante os anos noventa. E a segunda coisa é que um estudo desse porte dá uma melhor impressão da dinâmica do que a mídia fez na maior parte dos países do mundo. Os estudos de mídia nos Estados Unidos e na Inglaterra também são importantes e interessantes, mas somente aos dois países. E esses dois países, nós sabemos, vêm dominando os estudos sobre a mídia por muito tempo e isto atenua um pouco nossa compreensão do papel da mídia na sociedade mais "normal", se podemos dizer assim, que têm os Estados Unidos e a Inglaterra. A maior parte dos outros países não oferece uma história de estabilidade, de liberalismo democrático, etc., etc. Eles apresentam um espetáculo seguidamente de ditadura, de mudanças violentas, de insegurança econômica, etc. Para mim, a experiência dos países soviéticos, em particular nos últimos dez anos, é uma experiência que nós devemos estudar minuciosamente. Assim, se os pesquisadores brasileiros não sabem desta parte de minha obra, eu me entristeço um pouco. E se ás vezes eu não falo sobre as questões de racismo e mídia na antiga União Soviética e países do Leste Europeu, porque trabalhei sobre a Polônia também, é porque acredito que a importância desses sujeitos a serem estudados é tão evidente que não seja necessário nenhum comentário.

PW - E porque esse interesse sobre a antiga União Soviética sendo inglês e morando nos Estados Unidos?

JD - Eu sempre me interessei pela comunicação internacional global. Nos ano oitenta, todo mundo falava sobre o império americano. Eu em particular queria explicar a dinâmica do império soviético porque me parecia que havia certas instâncias similares entre os dois.

Por exemplo, eu fiz um estudo sobre a cobertura das mídias soviéticas sobre a guerra no Afeganistão durante os anos oitenta, e, no mesmo artigo, eu acrescentei a cobertura da mídia americana sobre a guerra em El Salvador, que se passava na mesma época. Porque me parecia que haviam muitas coisas em comum entre as duas. Mas em grande parte da mídia de esquerda, eles só se interessavam pelo ponto de vista do império americano. Eu achava importante este tipo de estudo, mas eu não acreditava que o ponto de vista americano era o único a ser visto e estudado. Foi por esse motivo que parti aos estudos sobre o império soviético.

PW - Porque o senhor utiliza tanto o termo mídia?

JD - Realmente, principalmente no livro Mídia Radical. É para insistir que nossa compreensão de mídia deva incluir um pouco mais do que normalmente pen- samos sobre ela. Como o rádio, o cinema, a imprensa, a televisão. Claro que é importante termos essas mídias, mas há outros tipos de mídia que devemos levar em consideração, como a dança, o teatro de rua, a tatuagem, as canções populares, etc. Todos esses processos eu vejo como mídia. É uma visão antropológica de mídia. Mas eu gostaria de instigar os pesquisadores em comunicação, e em particular em mídia, de pensar de forma mais abrangente a questão da mídia. Por isso eu utilizo o termo constantemente para de certa forma provocar este questionamento e lhes fazer pensar mais sobre o que realmente é mídia. Utilizando sempre exemplos de mídias, como por exemplo, as que eu citei, como a tatuagem. Uma tatuagem pode significar uma coisa muito importante para a pessoa tatuada. Pode significar um amor que passou e que não voltará mais, ou outro exemplo, nas prisões. As tatuagens dos prisioneiros significam que fazem parte de algum grupo, gangue, e são esses signos que fazem deles estar ou não em perigo lá dentro. Na época do nazismo também se utilizavam tatuagens para marcar as pessoas. É um exemplo terrível. Está aí o significado da mídia. Por que ela comunica. E a tatuagem comunica. Algumas podem ter um significado mais importante, outras nem tanto.

PW - O que é de fato uma mídia radical alternativa?

JD - O universo da mídia radical alternativa é bem maior do que se pode imaginar. A título de ilustração podemos citar alguns exemplos, que não se restringem aos meios de massa que estamos acostumados: TV, rádio, jornal, cinema. Podemos qualificar como mídia radical: as canções populares, como a música negra de vários países, a dança afro-americana, o grafite praticado por gangues de jovens, a cultura hip-hop, o vestuário - que eu denomino mídia têxtil, como os que eram utilizados na Guatemala durante a ditadura militar. As colchas sul- americanas que eram usadas de forma clandestina, broches e buttons. Adesivos de párachoques de caminhões, rock de garagem, teatro de rua, e aí falo sempre no brasileiro Augusto Boal e seu Teatro dos Oprimidos, vídeos populares, TVs comunitárias, rádios comunitárias e de acesso ao povo. E muitos movimentos que hoje se encontram na Internet. Para mim a mídia radical alternativa está onde a base de tudo é a comunicação entre pessoas ativas, e essa comunicação possa ou não, ser mediada por aparelhos.

PW - Quanto ao trabalho dos Movimentos Sociais, pode-se dizer que fazem mídia radical alternativa?

JD - Para mim, sim. Porque a "raiz" de radical, que vem do latim, significa que penetra na "raiz" das questões. Esse significado da palavra radical por vezes não me agrada quando se fala em movimentos sangrentos e coisas do gênero, mas de vez em quando se devem organizar tais enfrentamentos, como barricadas, por 
exemplo, para serem vistos. Um significado de "raiz" não existe se um confronto não tem nenhum significado político. Se este confronto se faz só porque é costumeiro. Nós devemos pensar se esta tática é apropriada a situação e não somente radical, mas no outro termo de radical. Isso é o que quer dizer para mim. Mídias alternativas? Muitas são. É só ser alternativo e pronto, ganha o rótulo. Mas ser radical é preciso que manifeste ao governo vigente que lhe oprime e não lhe deixa ser livre a ponto de expressar suas idéias.

PW - O direito a comunicação significa também direito a dignidade do cidadão?

JD - Sim, absolutamente. Porque se nós não temos esse direito sempre não somos o objeto de comunicação medi ática. Nós não temos dignidade. Nós nos tornamos simplesmente um pagante, um servo, um escravo, um funcionário. Mas se a cada vez que nós temos a possibilidade mesmo que não seja pessoal, mas social, estrutural de lançar e de poder falar aos outros de uma maneira ou outra com liberdade e sem medo, está aí uma verdadeira condição de fazer uma comunicação com dignidade e humanitária.

PW - Para o senhor o que é uma Mídia Cidadã e como fazer de fato esta mídia?

JD - Para mim a definição de Mídia Cidadã mais clara e útil é da minha amiga e colega colombiana Clemência Rodrigues, que é professora na Universidade de Oklahoma. Ela fala sobre "meios cidadãos". O que ela diz é que a cidadania completa deve incluir a possibilidade e a práxis de se comunicar na base da sociedade. Não uma base de comunicação vertical, mas uma comunicação lateral, horizontal, também vertical só que na direção reversa. Que nós possamos expressar nossos sentimentos, nossos olhares, visões e necessidades às autoridades econômicas e políticas. É claro que há bem mais que isto nesta definição. Não só isso. Um exemplo que Clemência Rodrigues dá sobre mídia cidadã, e que eu gosto muito, é de um grupo de mulheres de um bairro da cidade de Bogotá na Colômbia. É um grupo de mulheres simples, humildes, que experimentaram através de um pequeno projeto de vídeo a sensação de poder e confiança e do valor que tinham como pessoas, como cidadãs que antes desconheciam. Isto foi sendo descoberto por elas mesmas ao longo do processo, enquanto faziam o vídeo e se sentiam capazes daquele feito. Como isso acontecia? Elas se viam na própria tela e viam pessoas falando do mesmo jeito que elas e não como nas novelas da grande mídia. Mas com os seus acentos, seus jargões, com suas referências e suas ilusões também. E esta experiência de se ver a elas mesmas lhes deu uma sensação de ter muito poder. E para mim este é um grande exemplo do efeito de uma mídia cidadã, porque elas não queriam falar para o bairro inteiro, nem para Bogotá, muito menos para a Colômbia inteira, elas queriam falar só entre elas mesmo. Mas a experiência conferiu-lhes a confiança que não possuíam antes do projeto. E, adquirida esta confiança, ganharam força para acreditar no poder de transformação, e de agir no seu meio, na sua comunidade. E este é um efeito da mídia, não foi um efeito nacional, nem do bairro inteiro, nem um efeito sobre Bogotá, mas é um efeito muito, muito importante. E isso para mim é o que se pode falar de um bom exemplo. Do que se pode dizer em profundidade a essência do que é mídia cidadã.

A única reserva que eu tenho quanto a mídia cidadã é que com a quantidade de imigração e refugiados que nós temos atualmente, principalmente em determinados países, que não são cidadãos legalizados desses países em que vivem, é que eles não sejam excluídos. E que a expressão "mídia cidadã" não sirva só para os cidadãos oficiais, legalizados. Mas com esta ressalva o termo "mídia cidadã" é uma expressão muito útil.

PW - É a quarta vez que o senhor vem ao Brasil. Nesta visita conheceu dois projetos em Recife. O Coque Vive, que é um projeto em um bairro com cerca de $50 \mathrm{mil} \mathrm{ha-}$ bitantes com uma das rendas per capita mais baixa do país, e o projeto Oi Kabum, que profissionaliza jovens na área de vídeo, web design e fotografia. O que o senhor achou desses projetos?

JD - Para mim o projeto Oi Kabun é magnífico. É impressionante ver o profissionalismo com que esses jovens aprendem. E ver o senso de humor que eles têm para aprender coisas novas e que eles têm dinheiro para pôr em prática tudo ou quase tudo a que se propõem.

E o projeto na vila do Coque tem muito menos financiamento, mas, na minha opinião, ele tem duas vantagens. Uma das vantagens é que eles construíram tudo eles mesmos, sozinhos, sem dinheiro de fora, sem qualquer financiamento. Até o prédio onde estão! O projeto inteiro é sobre autogestão e autoconstrução, talvez isso faça com que eles tenham mais ou menos sucesso. Isso eu não posso dizer. Mas o projeto O Coque Vive tem raízes muito, muito profundas na favela onde eles se encontram. A segunda característica deste projeto é que, na tentativa de manter viva certa espiritualidade política e ecumênica, eles se dirijam não somente à capacitação dos jovens ao trabalho, mas de tentar alcançar a personalidade humana como um todo. E, para mim, a importância de reconhecer a pessoa humana como ser inteiro é um avanço colossal e é realmente muito impressionante.

PW - Em seu livro Mídia Radical, o senhor cita o teatro de Augusto Boal com muito conhecimento. Em sua palestra na IV Conferência de Mídia Cidadã falou com muita emoção a respeito de Paulo Freire. Qual a sua relação com esse pedagogo brasileiro? 
JD - Quando eu penso em Paulo Freire, eu penso em três coisas em particular. Uma delas é sua confiança absoluta na capacidade das pessoas comuns, ou seja, do povo, de se expressarem, de agir de forma singular nas suas vidas. A segunda é sua fusão entre o processo de comunicação e o processo de educação que tão freqüentemente as divisões das Universidades impõem algumas vezes certo muro de Berlim ou um muro da Califórnia, no Arizona, entre a educação e a comunicação. Há departamentos, escolas diferentes, talvez competição entre os dois por dinheiro de projetos e com isso freqüentemente nós temos uma grande dificuldade. Às vezes, quase nenhum contato existe entre pesquisadores e professores destes lugares, o que causa um grande malefício que Paulo Freire já discutia em sua época. E em terceiro, a determinação que Paulo Freire tinha. Ele agia sem jamais se deixar levar pelo medo disso ou daquilo, nem do Estado ou da repressão. Parecia que nada segurava Paulo Freire em seus ideais. Ele sempre continuou no mesmo caminho. Por isso ele é um exemplo para todos nós. Pessoalmente eu só o encontrei uma única vez, mas, quando o vi, ele irradiava um calor humano, um amor que era realmente intenso.

PW - Qual a diferença atualmente entre Indústria Criativa e Indústria Cultural?

JD - O termo "Indústria Cultural" se deriva dos Frankfurtianos Horkheimer e Adorno, que todos já conhecem muito bem. Já o termo "Indústria Criativa" é como fosse um avanço conceitual. Para mim este termo é simplesmente um termo de conveniência das políticas governamentais, porque é um termo que justifica os gastos com as zonas criadas nas cidades nas quais as atividades culturais e criativas florescem e que se espera promover o turismo e o crescimento econômico.

PW - O senhor acredita que o desejo dos jovens que trabalham hoje por uma mídia, seja ela radical, alternativa ou independente, é de um dia poder estar do outro lado, quero dizer, da grande mídia?

JD - Isto é possível. Temos exemplo disso na França com o Jornal Liberation, que foi criado nos anos sessenta como um jornal radical e atualmente é um jornal tão bem estabelecido na grande mídia parisiense e francesa quanto qualquer um de seus concorrentes. Outra rádio na Colômbia teve a mesma trajetória. É muito mais freqüente do que imaginamos que pequenas mídias alternativas sirvam como um meio de capacitação para pessoas que depois acabam na grande mídia. Para mim isso não chega a ser uma tragédia, nem uma traição. Eu espero que muito dentre eles levem a experiência que tiveram nesses meios alternativos e que possam, com essa experiência, fazer um jornalismo melhor.

Nós vivemos num mundo complexo. Atualmente, para mim há efetivamente uma espécie de justiça quando alguém simples, pobre, que vivia numa comunidade esquecida e trabalhava numa mídia alternativa é aceita numa grande mídia. É um tipo de abertura, não uma revolução, mas um tipo de justiça. Alguém de um mundo antes não aceito que agora entra num outro mundo antes inacessível a ele por seus próprios méritos. É justiça, não traição. Olhando por outra dimensão, é que realmente a maioria dos militantes de mídia alternativa normalmente tem um perfil de serem solteiros, relativamente jovens, e têm tempo suficiente para se dedicar ao trabalho. Quando isso muda, quando se casam, tem filhos, por exemplo, eles não podem mais impor esta austeridade política sobre os outros, sobre a esposa ou o marido, e aí as coisas começam a mudar. Então eles começam a procurar outros tipos de emprego e acabam caindo nas grandes mídias. É normal. Não se pode julgar. É uma simples questão que as condições de vida mudam. E há também um problema subjacente que de tempos em tempos a mídia alternativa é organizada quase que somente por gente jovem. Eu não desconfio em hipótese alguma do talento e da energia desses jovens. Pelo contrário, eu aprecio muito que eles estejam lá militando por uma nova mídia. Mas para que essa mídia fale a todos é preciso contrabalançar essas pessoas engajadas, que ela não seja feita somente por gente jovem, mas de todas as idades, idosos, mulheres, homens, etc. Essa é uma das fraquezas da mídia alternativa. Não é um erro terrível, mas que deve ser corrigido.

PW - Quais são os planos de pesquisa do senhor para os próximos anos?

JD - No momento, estou editando uma Enciclopédia de Movimentos Sociais. Este projeto, que está na primeira fase de edição, prevê incluir múltiplas experiências através do planeta. Nós já fizemos alguns estudos de mídia radical em vários países da Europa, incluindo a Rússia, e os Estados Unidos. Há aí uma limitação de financiamento, de tempo, e também questão de línguas. Mas esta Enciclopédia de Movimentos Sociais vai contar com pesquisadores do mundo inteiro. A idéia é que ela receba contribuições de lugares inimagináveis, não só de lugares e centros de pesquisa já conhecidos. Essas contribuições devem vir da China, da Indonésia, das regiões arábicas, que tem muito a contribuir com os exemplos dos movimentos dos povos berberes e de outras partes do mundo mais distantes. Eu espero apresentar ao público leitor experiências realmente diferentes a que eles estejam acostumados. Experiências ricas no sentido de trocas de valores e significados. Nós teremos com esta Enciclopédia um arquivo, um tesouro de experiências sobre movimentos sociais em diferentes partes do mundo, o que vai facilitar muito o trabalho para os pesquisadores da área, porque além de em único volume você poder conhecer realidades de diversos e diferentes lugares, poderá também fazer comparações e tirar suas próprias conclusões. Por enquanto, nós, 
pesquisadores que trabalhamos com esse objeto, não temos nada parecido com o que será a Enciclopédia de Movimentos Sociais. Eu espero que este livro seja muito útil aos militantes e pesquisadores de várias partes do mundo.

PW - O senhor utiliza muito também o termo "mídia dos movimentos sociais". Esse é um novo conceito de mídia para o senhor?

JD - Sim, eu o estou utilizando porque na verdade acho que todos os termos usados são deficitários em algum ponto. Atualmente estou preferindo usar este termo porque ele reúne a realidade da mídia com a realidade social e estrutural. É como se eles não estivessem distantes e autônomos do contexto e eu vejo este contexto como sendo uma peça chave para o funcionamento desta mídia.

PW - O senhor é professor tanto na Inglaterra quanto nos Estados Unidos há mais de quarenta anos. Têm mágoas com a academia de alguma forma?

JD - Sim, claro A academia está cheia de pessoas excelentes, de bons colegas, bons amigos, e principalmente excelentes profissionais, mas estruturalmente minhas mágoas são com as determinações das pessoas, das autoridades na academia que utilizam isso para servir o poder. Dos que fazem das Universidades um lugar de neoliberalismo, da destruição do pensamento independente. Outra coisa que me incomoda é a divisão de classes em grande parte dos campi universitários que eu conheço. Existe como se fosse uma escada: os empregados, os estudantes e os professores e, na minha experiência, as secretárias, as pessoas que abrem a porta, que fazem a faxina, que trabalham na cozinha, e etc., são vistos pelos outros, especialmente os professores, mas também pelos alunos, que serão profissionais um dia, como de semi-humanos. Há aí um elemento muito forte de sexismo, porque normalmente as secretárias de departamentos são mulheres. Não estou generalizando. Temos mulheres como professoras nas salas de aula que agem da mesma forma quanto aos que falei antes. Não é um caso de sexismo, mas de discriminação. E eu acho que não podemos ter esse tipo de problema logo na academia, um lugar formador de cidadãos. Para mim estes são alguns sérios problemas da academia e que ao longo destes quarenta anos tem me incomodado bastante. Outra coisa que eu acho que deveria mudar na academia é a divisão de conhecimentos. Nós não deveríamos ficar restritos ao Departamento de zoologia, lingüística ou química. Há um abismo enorme entre as ciências, de se falarem mais umas com as outras, de se trocarem mais experiências, as Ciências Humanas com as Ciências Exatas parece que uma deve estar bem longe da outra. E eu, particularmente, acho que devíamos nos conhecer melhor. Acho que a pesquisa de uma forma mais abrangente sairia ganhando com isso. Mas se criou esse muro. As minhas mágoas com a academia se concentram aí.

PW - Há cerca de vinte anos o cinema indiano começava a crescer de forma alternativa e industrial se autodenominando Bollywood. Como o senhor vê atualmente os fenômenos Nollywood e Hallyu?

JD - Nollywood hoje é uma indústria de vídeo-filme situada na região de Lagos na Nigéria, e é um termo que segue outras indústrias similares como Gana, Quênia, Tânzania ou Uganda, etc. Nollywood significa também o fato dos vídeos-filme da Nigéria, em particular, não circularem apenas no continente africano, mas também em cidades dos Estados Unidos e de outros países como a Inglaterra onde há uma forte presença nigeriana. É um fenômeno global atualmente bastante interessante porque estes vídeos-filme são muito populares, baratos e que começou de uma verdadeira indústria indígena africana do cinema. É uma mistura entre cinema e vídeo porque eles não são apresentados em salas de cinema, mas todo mundo vê em casa, em bares, em cidades distantes das capitais. E seu financiamento é somente de nigerianos que fazem esses filmes. Não existe dinheiro do estrangeiro, de banco nigeriano, do governo nigeriano através de auxílio a cultura. Isso não existe. Tudo o que é feito é feito de forma autônoma. Eu creio que essa indústria tenha seu sucesso justamente por não sofrer intervenções. É o exemplo de uma indústria local que hoje está global, que a influência de seu trabalho e sua distribuição ganhou um espaço enorme no mercado. E Hallyu é como podemos chamar a onda coreana, que podemos descrever como um movimento de televisão, de canções e também de cinema coreano que são muito populares não só na Coréia, mas no Japão e na China. $\mathrm{E}$ aqui temos uma coisa muito interessante entre os três países. A Coréia é o menor destes três países, mas sua indústria cultural pode ser vista atualmente até em festivais de cinema mundial. Mais uma vez podemos falar de uma indústria local que se torna global que assim como Nollywood. Estão fora da rota dos países da Indústria Cultural, mas se estabeleceram e fazem sucesso. O que isso quer dizer? Não precisa estar em Hollywood para se fazer filmes e sucesso waAmEcos 